\title{
A STUDY ON TOXIC EFFECT OF CHEMICALS AND CONTROL STRATEGIES
}

\author{
Thaneshwar Subedi ${ }^{*}$ \\ ${ }^{1}$ Department of Chemistry, Prithvi Narayan Campus, Tribhuvan University, Pokhara \\ *For correspondence: thaneshworsubedi@gmail.com
}

\begin{abstract}
Poisons are substances that can cause death, injury or harm to organs, tissues, cells and DNA usually by chemical reactions or other activity on the molecular scales, when an organism is exposed to a sufficient quantity. The objective of the study was to identify the toxic chemicals, to study their poisoning effect and present poisoning reduction strategies and then precautions. Analytical research method was used for conducting this research. This study is focused on the toxicity of major harmful chemicals such as hydrogen sulphide, carbon monoxide, carbon dioxide, chloroform, Sulphur dioxide, ammonia, formaldehyde, hydrogen cyanide, mercury, arsenic, cadmium and their compounds, catalyst, inert gases, insecticides, antidote which have been used in chemistry laboratories and in other different fields. Students from higher education to research levels are suffering from toxic laboratory chemicals. Workers in chemical industries are being intoxicated from poisonous reactants, intermediates and final products. Farmers are directly exposed to chemical fertilizers, insecticides, pesticides, herbicides, and fungicides. Different types of toxic irritant, sensitizer, asphyxiates, anesthetics, narcotics, systemic poisons, respiratory fibrogens, and carcinogens are mainly responsible for animal poisoning and environmental pollution. Poisoning from toxic chemicals can be controlled by the strategies like substitution, mechanical handling, process changing, suppression, segregation, ventilation, personal protection, medical supervision and biological monitoring. Immediate accidental poisoning can be managed by using respective antidotes and obeying specific precautions.
\end{abstract}

Key words: Antidote, carcinogens, carboxyhaemoglobin, formalin, pollutants, toxic chemicals

\section{INTRODUCTION}

The toxicity of a substance is its ability to cause harmful effects. Now a day hazardous substances are used in many work places. Hazardness of the substance depends on its toxicity, route of exposure, dose, duration, reaction and interaction, and sensitivity of body. Normally, exposure occurs through inhalation, skin or eye contact and ingestion. A poison is any substance that is harmful to the body when eaten, breathed, injected or absorbed through the skin. Any substance can be poisonous if enough is taken (Tarlok, et al. 2015). These poisons can enter our body through three routes: by mouth (injection), by inhalation (into lungs) and by direct absorption through skin to blood system. These effects can strike a single cell, a group of cells, an organ system or the entire body. Toxicity of substance depends on its chemical structure, the extent to which the substance is absorbed by the body and the body's ability to detoxify the substance and eliminate it from the body.

Poisoning is a major health problem in every fields of the world. Occupational exposure to industrial chemicals, pesticides, accidental or intentional 
exposure to household to pharmaceutical products and poisoning due to venomous animals, toxic plants and food contamination, all contribute to morbidity and mortality (Lal et al, 2003). According to Tarlo et al. (2015), poisoning is divided into four broad categories: Pharmaceutical poisoning like paracetamol, aspirin, benzodiazepines, phenyltoin, tricyclic, antidepressants, barbiturates, opioids etc. Insecticides and pesticides like organophosphate, chlorine, pyrethroids, superwatarin, furadon, parathion and endosulphan poisoning. Plants and animals poisoning like snake or scorpion bite, bees or wasps sting, insect sting, oleander, dhatura and oduvanthalai. Inorganic, organic and biological chemical poisoning such as mercury, arsenic, lead, copper, sulphur, hair dyes, rotenone, pyrethrum, nicotine, neem oil, bacteria and viruses. Carson and Mumford (2002) classified the toxic chemical into seven types. Irritant Chemicals: Irritant chemicals causes inflammation and corrosive action in the affected area depending on the concentration of chemicals. Sensitizers: Sensitizer chemicals may bring about violent allergic ill effect on skin, respiratory system, body's immune system within few days to few years. Asphyxiants: Asphyxiants interferes the body's oxygen uptake mechanism. Anesthetics and narcotics: Anesthetics and narcotics exert a depressant action on the central nervous system. Systemic poisons: Systemic poisons attack the critical organs like kidney, liver, blood and bone marrow than the initial site of contact. Respiratory fibrogens: The hazard of particulate matter is influenced by the toxicity, size and morphology of particle. The critical size of dust/ aerosol particle is 0.5 $\mu \mathrm{m}$ to $0.7 \mu \mathrm{m}$ which are deposited in the respiratory bronchioles and alveoli. Deposition of silica or asbestos inside the surface of lungs, a scar tissue (collagen) may build up which reduces elasticity of lungs and impairs breathing. Carcinogens: Cancer causing chemicals are called carcinogens.

This study discusses the laboratory poisoning and health hazards of laboratory related persons.
The research mainly discusses thee toxic effect of some common laboratory chemicals like mercury and its compounds, arsenic and arsenic compounds, lead compounds, cadmium compounds, inorganic cyanides, oxalic acid and its salts, carbon monoxide, carbon dioxide, oxides of nitrogen, ammonia, sulphur dioxide, hydrogen sulphide, catalysts used in lab and chemical industries, inert gases, insecticides, carcinogens, and antidotes. Hydrofluoric acid, benzene, chloroform, formaldehyde, uranium compounds, perchloric acid, chlorates, bromine, carbon disulphide, phenols, aromatic nitro compounds, sodium metal, strong acids, From the knowledge of harmful chemicals in chemistry laboratory and their harmful effect in the study, the laboratory involving persons will be careful and adopt proper precautions. This study will provide insights for students, teachers, laboratory staff, and worker in chemical industries, chemical suppliers and other related persons (Vogel, 1989).

\section{MATERIALS AND METHODS}

The present study was based on the curriculum of higher secondary level to research level in chemistry, environmental pollutants, and pesticide producing industries. The list of chemicals used for the present research was collected on the basis of curriculum of master, bachelor and higher secondary level of science in chemistry, theoretical and practice chemistry books of different level of university and school, journals, articles, research reports, technical reports, projectreports, conference papers, media articles, internet search engines and reports of many authors, dictionaries, monographs, chemicals required in chemistry laboratories, operational manual of scientific instruments, chemicals, explosives etc. Analytical research method was used for conducting this research. The list of harmful chemicals, their poisoning 
effect, control strategies and ways of controlling their poisoning effects are discussed.

\section{RESULTS AND DISCUSSION}

Large number of chemicals used in chemistry laboratories are responsible for health hazards of chemistry students, teacher, laboratory workers, and persons who involves for labeling, storage and supply of chemicals (Vogel, 2001). Besides the chemical used in chemistry laboratory, pharmaceutical poisons, insecticidal poisons, pesticide poisons, plants and animal poisons industrial and fibragenous poisons etc. are also responsible for social and environmental poisoning. Out of these chemicals, the selected much more harmful chemicals and their poisoning effect is described below.

\section{Hydrogen sulphide $\left(\mathrm{H}_{2} \mathrm{~S}\right)$}

In the higher secondary and university levels $\mathrm{H}_{2} \mathrm{~S}$ is the most commonly used laboratory reagent. It is prepared in laboratory by the action of dilute sulphuric acid on iron sulphide. In chemistry laboratory, $\mathrm{H}_{2} \mathrm{~S}$ is used as reducing agent and for qualitative salt analysis in bachelor and master levels of Tribhuvan University. $\mathrm{H}_{2} \mathrm{~S}$ is also produced in air by the reduction of sulphates, organic Sulphur compounds, volcanic activity, decay of animals and vegetable matter. It is also produced in air from coke ovens, petroleum industry, paper mills, rayon manufacturing plants, tanning industry and sewage treatment plants.

Hydrogen sulphide is rotten egg smelled very toxic gas and objectionable even at low concentrations. Its mild exposure in laboratories causes headache. conjunctivitis, sleeplessness, pain in the eyes, irritation of respiratory track, respiratory paralysis, malodorous. In high concentration it may lead to blockage of oxygen transfer, poisoning cell enzymes, and damaging nerve tissues [Vogel, 2001].

Hydrogen sulphide poisoning can be controlled by producing only limited amount of $\mathrm{H}_{2} \mathrm{~S}$ related tests in fume cupboard. Its effect can be reduced by burning or passing the exhaust $\mathrm{H}_{2} \mathrm{~S}$ gas through water to get less harmful Sulphur (Jain, 1993). Harmful effect of $\mathrm{H}_{2} \mathrm{~S}$ can also be reduced by burning it in excess of air to get $\mathrm{SO}_{2}$ and removing $\mathrm{SO}_{2}$ by using chemical scrubbers.

\section{Carbon monoxide (CO)}

In chemistry laboratories, carbon monoxide is released during the stem reforming and incomplete combustion of fossil fuels. It is also produced in laboratory atmosphere during the reduction of $\mathrm{CO}_{2^{\prime}}$ tests of oxalates, acetates, formats, ferrocyanide $\left.\left.\left[\mathrm{Fe}(\mathrm{CN})_{6}\right)\right)^{4}\right]$ and citrate $\left[\mathrm{C}_{6} \mathrm{H}_{5} \mathrm{O}_{7-}^{3--}\right]$ ions. Carbon monoxide is also released on atmosphere by dissociation of $\mathrm{CO}_{2^{\prime}}$ from automobile and jet engine exhaust, volcanic process, blast furnace, mines, tobacco smoking, marsh gas production, seed germination, industries and agriculture burning.

Carbon monoxide poisoning causes toxicity, increased proneness to accidents and blood poisoning. Carbon monoxide combines with hemoglobin $(\mathrm{Hb})$ in blood to form carboxyhemoglobin which reduces oxygen carrying capacity of blood and hence lead to suffocation and then death. Carbon monoxide inhibits the nitrogen fixing ability of bacteria in plants. Harmful effect of carbon monoxide in chemistry laboratories can be reduced by replacing the fossil fuel as energy source by hydroelectricity and solar energy, by conducting the carbon monoxide involving experiments in fume cupboard, by adjusting the anti-carbon monoxide pollution catalyst in the $\mathrm{CO}$ exhausting source, by increasing the air-fuel ratio in the combustion engine and by conducting the student awareness in chemistry laboratories (Rastogi, 1993).

\section{Carbon dioxide $\left(\mathrm{CO}_{2}\right)$}

It is acts as an asphyxiant due to displacement 
of air resulting in the oxygen deficiency. It is sources were fires, use as an inert gas, discharge of $\mathrm{CO}_{2}$ extinguishers, uses of solid 'Cardice' as cryogen, fermentation, neutralization of acids with carbonates and bicarbonates, as byproducts from the synthesis of ammonia and hydrogen. Its percentage in air is 0.03 up to $0.5 \%$ concentration no special symptoms and no permanent damage, when $2 \%$ concentration in air breathing rate increased by $100 \%$, at $8 \%$ concentration headache, vomiting, dizziness, breathing difficulties, and of $10 \%$ concentration causes headache, vomiting, dizziness, disorientation, unconsciousness and death after few minutes.

\section{Chloroform $\left[\mathrm{CHCl}_{3}\right]$}

In chemistry laboratory, chloroform is used as an excellent solvent for fats, waxes and resins. It is used as laboratory reagent to test the primary amines, to prepare chloretone, chloropicrin, salicyaldehyde etc. Chloroform vapour is highly poisonous. Inhalation of chloroform vapour causes unconsciousness and death in case of high dose.

\section{Sulphur dioxide $\left(\mathrm{SO}_{2}\right)$}

Sulphur dioxide gas is produced in laboratory during the combustion of fossil fuels by the oxidation of $\mathrm{H}_{2} \mathrm{~S}$ in air, and during the salt analysis. In laboratory, it is used as oxidizing agent, bleaching agent, reducing agent, and refrigerant. In the atmosphere, $\mathrm{SO}_{2}$ is accumulated from volcanic sources and roasting process, from fuel burning, petroleum industries, oil refining, power houses, sulphuric acid plants etc. $\mathrm{SO}_{2}$ pollution causes irritation eyes, nose, throat, formation of cough, respiratory and sensory irritation, formation of acid droplets in air, corrosion of equipment and marble in laboratory, lung diseases like lung cancer etc.

Harmful effect of $\mathrm{SO}_{2}$ can be reduced by replacing fossil fuels by hydroelectricity and solar energy, by conducting the $\mathrm{SO}_{2}$ involving tests in fume cupboard and by removing $\mathrm{SO}_{2}$ from fuel gases using chemical scrubbers (lime, magnesium hydroxide, sodium hydroxide) and by conducting the awareness about source of production and harmful effect of $\mathrm{SO}_{2}$.

\section{Ammonia $\left(\mathrm{NH}_{3}\right)$}

In chemistry laboratory, it is used as laboratory reagent in qualitative salt analysis, as cleaning agent for glass and furniture, as refrigerant in ice plant. It is also used for manufacture of $\mathrm{HNO}_{3}$, $\mathrm{Na}_{2} \mathrm{CO}_{3}$, fertilizers (urea, ammonium sulphate etc.). In the atmosphere, it is accumulated from coke oven, chemical industries, refineries, fuel incineration and animal farming (Vogel, 2001). Ammonia is corrosive to mucous membrane and it damages respiratory track and eyes.

\section{Formaldehyde (HCHO)}

Formaldehyde is used as laboratory reagent in laboratory. In biology formalin (40\% aqueous solution of formaldehyde) is used for preservation of biological specimens. In hospitals and biological museum, formalin is used for preservation of dead body for long time. In the industries it is used for manufacture of bakelite, dyestuff, resins, for silvering mirrors, in leather industry for tanning hides. Formaldehyde is released in air as automobile exhausts, from waste incineration, combustion of fuels, photochemical reactions. Pollution of formaldehyde in laboratory causes irritation of eyes, throat, respiratory track, skin (Vishnoi, 1979).

\section{Hydrogen Cyanide (HCN)}

Inorganic cyanide $(\mathrm{CN})$ cyanides of alkali and alkaline earth metals are soluble in water due to hydrolysis to form HCN which is volatile and highly poisonous. $\mathrm{HCN}$ is released in laboratory during the heating test of uric acid. $\mathrm{HCN}$ is also 
evolved on heating cyanide with acid. $\mathrm{HCN}$ is also produced on boiling sodium extract with conc. $\mathrm{HNO}_{3}$ of nitrogen is present in sodium extract. In laboratories, $\mathrm{KCN}$ is required to test the $\mathrm{Ni}^{2+}, \mathrm{Fe}^{2+}, \mathrm{As}^{3+}, \mathrm{Cu}^{2+}, \mathrm{Ag}^{+}, \mathrm{Pb}^{2+}, \mathrm{Hg}_{2}{ }^{2+}$ and thiocyanate ions. To reduce the poisoning effect of $\mathrm{HCN}$ (or $\mathrm{CN}^{-}$) in laboratory, experiments involving cyanide ions should be carried out in fume cupboard.

\section{$\mathrm{Hg}$ and its compounds}

Mercury vapour and all of the mercury compounds are toxic. Mercury vapour is evolved by heating mercury compounds with sodium carbonate. During the analysis of basic radical $\left(\mathrm{Hg}_{2}{ }^{2+}\right.$ or $\left.\mathrm{Hg}^{2+}\right)$ different types of mercury compounds are involved. These are harmful mercury compounds. Mining, refining of mercury, pesticides, coal burning are other mercury poisoning sources. Mercury poisoning causes serious illness, nervous disorder, immobilize protein in blood system, interfere transport phenomenon across cell membrane, muscle weakness, impairs hearing and eye sight, mental retardation, minimata diseases, immediate death in case of high dose. Harmful effect of mercury and its compounds can be reduced by conducting experiments in fume cupboard and by replacing poisonous mercury compounds by alternative chemicals.

\section{Lead and its compounds}

Lead and most of the lead compounds are poisonous. Various harmful lead compounds are used in the chemistry laboratory during the analysis of $\mathrm{Pb}^{++}$ion. Other lead poisoning sources are automobile emissions, lead smelters, burning of coal and oils, lead arsenate, pesticides, smoking, mining and plumbing (Nagashanmugam and Srinivasan, 2010). Lead poisoning causes anemia, headache, mental deficiency, damage of liver, kidney, intestine, brain, coagulation of protein, abnormalities in fertility and pregnancy and disturb DNA molecule.

\section{Arsenic and Its compounds}

Arsenic and its compounds are toxic. Inchemistry laboratory, during the analysis of basic radical $\left(\mathrm{As}^{3+}, \mathrm{As}^{5+}\right)$ various arsenic compounds formed. Other arsenic poisoning sources are arsenic containing fungicides, pesticides, herbicides, metal smelters, by- products of mining activities, chemical wastes etc. Arsenic poisoning causes skin diseases, intermittent fever, interfere the transport phenomenon across the membrane, deactivate enzymes, coagulation of protein (Vogel, 2001).

\section{Cadmium and Its compounds}

In chemistry laboratory, cadmium is detected as basic radical. Other cadmium polluting sources are cadmium producing industries, welding, by-products from the refining of $\mathrm{Pb}, \mathrm{Zn}$ and $\mathrm{Cu}$, fertilizer industries, pesticide manufacturing industries, nickel-cadmium batteries, production of TEL, ornamental factories etc. All the compounds of cadmium are toxic. Inhalation of fumes causes bronchitis, gastric and intestinal disorders, disorder of heart, liver and brain. Chronic and acute poisoning may result anemia, hypertension, bone marrow disorder and cancer (Cotton and Wilkinson, 1993).

\section{Catalyst}

Catalysts are used in chemical laboratories and industries to increase the rate of reaction. Aluminum chloride used in Friedel-crafts reaction to manufacture detergent alkylate, agrochemicals and drug and resin manufacture. It has irritation effect due to formation of $\mathrm{HCl}$ in moisture. Aluminum oxide is used in fluid cracking and auto exhausts and has nuisance effect. Aluminum alkyls and chromic oxides are used in Grignard reaction having lung damaging and carcinogenic effect $\left(\mathrm{Cr}^{6+}\right)$. For 
high pressure production of aldehydes cobalt is used as catalyst which has lung irritation and respiratory sensitization effect. Siderosis effect of ferric oxide catalyst, which used as oxidant, was observed. Molybolenum compounds are used in various organic reactions like oxidation of methanol to formaldehyde which has irritation of eyes and respiratory tract. Nickel compounds and nickel carbonyl are used in hydrogenation and carboxylation $\mathrm{f}$ acetylene and alcohols respectively has skin sensitization, carcinogenic and acute respiratory failure effects. Similarly, platinum compounds are automobile exhaust catalyst having sensitization dermatitis. Vanadium catalyst is used in pollution control (removal of hydrogen sulphide) and manufacture of sulphuric acid has respiratory irritation (green-black tongue) effect.

\section{Inert gases}

Most toxicological inert gases, e.g. nitrogen, helium, argon generates oxygen-deficiency atmospheres. These gases concentration increases in the working atmosphere from the use of nitrogen or argon to exclude air from vessel, use of carbon dioxide as fire extinguisher, generation of nitrogen and helium gas from cryogenic liquids, leakage of argon from argon are welding set, from the formation of rust inert the closed steel tank and neutralizing contents with carbonates and bicarbonates.

\section{Insecticides}

Insecticides may be in the form of concentrate liquid (requiring dilution, with water or solvents) solutions, powders, granules or pastes or pressurized or liquefied gases. All such chemicals are toxic to varying degrees so that exposure via inhalation or ingestion, and in many cases via skin absorption should be minimized. Organophosphate insecticides (azodrin, diazinon, ethion, NPP etc), chlorinated hydrocarbon insecticides (aldrin, DDT, TDE, etc.), insecticides (cryolite, DN-111, zineb etc), rodenticides (sodium fluoroacetate, thallium sulphate), fungicides (ferbam, nabam, ziram etc) and herbicides (2, 4 -D, 2, 4, 5 -T etc) are toxic. (Ministry of Health, 2011).

\section{Antidote}

An antidote is a chemical or drug that will counteract the effect of poison. Antivenin or antivenom is a kind of antidote for the venom resulting from the bite or sting of a poisonous creature. Activated chemical is used as antidote for a wide range of poisoning causes. It absorbs some poisons and prevent them from passing into the blood stream. Ethanol, insulin, and sodium bicarbonate serve as antidote for some poisons. Only forty specific antidotes are available for use in acute and chronic poisoning (Betten et al., 2006; Bowden et al. 1997).

\section{Toxic Chemical Control Strategies}

Strategies for reducing the risk from a toxic chemical depend upon its nature (i.e. toxic, corrosive, dermatitis) and extent generally. A combination of following measures may be appropriate.

Substitution: Hazardous or toxic chemicals or mixtures may be replaced by safer or less toxic materials which are less volatile and dusty. Substitution is also applicable in synthetic route to avoid toxic reactants, solvents, intermediates, by-products or wastes.

Minimization of Inventory: Risk from toxic chemicals can be reduced by minimizing the toxic chemicals in storage and in process. Dilute practicable solutions can be used than concentrated.

Mechanical handling: Release and exposure of toxic chemical can be reduced by appropriate mechanical handling. For example, transfer via pipelines, by using corrosion-resistant containers, enclosed transfer by pressurization or vacuum, by using enclosed belt conveyors, 
chutes or pneumatic conveyors for solids, transfer of solid by screw feeders, transfer of solid in sealed containers, by using automated vessel or equipment cleaner.

Process Change: Modification of chemical process or manufacturing operation can reduce risk. For example, purification of raw materials, use of solutions, slurries, pellets, granules or dust free powder instead of dry powders, transfer of toxic chemicals in sealed containers or impermeable bags.

Suppression: Release of dusts, vapor, liquid (mists, sprays) can be reduced by suppression methods like pre-wetting of powder or fibrous solids, uses of tanks or other portable container to reduce exposed liquid surface, lowering the operating temperature of process liquid, by making vapor recovery system on storage tanks. Monitoring of equipment operation and of process parameter. Regular monitoring including electrical power system, equipment vibration, temperature (low, high), pressure (low, high), flow rate of process, $\mathrm{P}^{\mathrm{H}}$, liquid level, atmospheric concentration of specific pollutants can reduce the risk from toxic chemical.

Segregation: It is a common means of controlling toxic risk or restricting working area exposed to them. Segregation induces combination of distance (spacing of equipment, operating stations, storage, buildings), physical barriers (separate rooms, use of screens) and time of every process.

Containment: Adequate instrumentation like temperature indicator, high temperature alarm, pressure indicator, high pressure alarm, level gauge, etc should be included in the storage tanks.

Local exhaust ventilation: Risk from toxic chemicals can be reduced by keeping exhaust ventilation in working room like laboratory fume cupboard, lip extraction at anticipated points of leakage etc.
Personal Protection: Use personal protection equipment (PPE) like protective gloves, eye wear respirators, laboratory coats and aprons etc. to reduce the risk from toxic chemical when working environment is poisoning.

Personal hygiene: Personal hygiene like washing and drying hands, bathing, using of barrier cream in skin, use of cleaners of adsorbent for skin chemicals, separate area for eating, drinking or smoking from work area are essential.

\section{CONCLUSIONS}

Large numbers of chemical reagents are used in chemistry laboratories and most of them are harmful. Some harmful poisonous chemicals are hydrogen sulphide, carbon monoxide, carbon dioxide, chloroform, Sulphur dioxide, ammonia, formaldehyde, hydrogen cyanide, mercury, lead, arsenic and cadmium, catalyst, inert gases, insecticides antidotes. The different chemicals have different types of poisoning effect.

These poisoning effects can be reduced by obeying precautions: All involving person must use apron, mask, suitable gloves, safety glasses in chemistry laboratory. Students must be supervised during practical work by adequately trained personal. It is worthwhile to spend some time at the beginning of the practical course on explaining safety measures in the laboratory, including practice with fire extinguishers. Chemists and students should have well information about the involving chemicals and related experiments. If necessary or if in doubt, one must use fume cupboard with good ventilation to perform the chemical tests. User of the chemistry laboratory should be aware of the fact that almost all of the reagents involved in the qualitative inorganic analysis are poisonous and some of the operations can be dangerous. Special care is needed for handling cyanides, 
compounds of mercury, cadmium, arsenic, and working with hydrogen sulphide. Students must be well familiar with the related tools and technique used in chemistry laboratories.

\section{REFERENCES}

Betten, D. P., R. B. Vohra, M. D. Cooketal. (2006). Antidote use in the critically ill poisoned patient. J Intensive Care Med. 21(5): 255-277.

Bowden, C. A., and E. Krezelok (1997). Clinical applications of commonly used contemporary antidotes. A US Perspective Drug Sat. 16(1): 9-47.

CDC (2017). Master of Science Chemistry Curriculum. Kathmandu: Curriculum Development Centre, Institute of Science and Technology.

Carson, P., and C. Mumford (2002). Hazardous Chemicals Handbook, Great Britain: Butterworth-Heinemann Publications. Company Limited.

Cotton, F. A., and G. Wilkinson (1993). Basic Inorganic Chemistry ( $8^{\text {th }}$ ed.). New Delhi: H.S. Poplai for Wiley Eastern Limited.

Dhaubhadel, S. P. (2003). Practical Chemistry - I ( $1^{\text {st }}$ ed.). Kathmandu: M. K. Publishers and Distributers.

Dhaubhadel, S.P. (2005). Practical Chemistry- III ( $1^{\text {st }}$ ed.). Kathmandu: M. K. Publishers and Distributers.

Dhoubhadel, S. P., K. P. Pradhan, and S. M. Joshi (1989). Practical Chemistry (4 $4^{\text {th }}$ ed.) Kathmandu: The Authors.

Finar, I. L. (1990). Organic Chemistry (Volume-1) $\left(6^{\text {th }}\right.$ ed.). Singapore: Longman Singapore Publishers (Pvt.) Ltd.

Jain, S. K. (1993). Conceptual Chemistry (1 $1^{\text {st }}$ ed.). New Delhi: S Chand and Company Ltd.

John, D. (2004). Oxford Dictionary of Chemistry ( $5^{\text {th }}$ ed.). India: Oxford University Press.

Lal, S. B., S. S. Al-Wahaibi, M. M. Al-miyami, and K. Al-kharusi (2003). Profile of acute poisoning cases presenting to health centres and hospitals in Oman. La revue de santé la mediterranee orientale. 9 (6): 944-954.

Madan, R. D. and B. S Bisht (2000). I. Sc. Chemistry ( $3^{\text {rd }}$ ed). New Delhi: Oxford and 1BH Publishers Co. Pvt. Ltd.

Ministry of Health (2011). Management of Poisoning. Singapore: Ministry of Health. http://www.moh.gov.sg/cpg

Nagashanmugam, K. B. and K. Srinivsan (2010). Evaluation of lead (II) removal by carbon derived from ginelly oil cake. Asian Journal of Chemistry. 22(7): 5447-5462.

Rastogi, S. C. (1999). Biochemistry (5 $5^{\text {th }}$ ed.). New Delhi: Tata McGraw-Hill Publishing

Salmeron, R.A., D. R., Muner, and S. Nouguexarau (2009). Use and cost of antidotes in two hospital emergency departments. Emergenciae. 21 (3): 276-282.

Sthapit, M. K. and R. R. Pradhananga (2055). Experimental Physical Chemistry ( ${ }^{\text {st }}$ ed.) Kathmandu: Taleju Prakashan.

Tarlok, S., A. Sharma, P. Shira, K. Sourabh and D. Shalini. (2015). Introduction to Poisoning: A systematic review. International Journal of Pharmacy Teaching and Practice. 6 (4): 26092619.

Vishnoi, N. K. (1979). Advanced Practical Chemistry ( $2^{\text {nd }}$ ed.) Kanpur: Vikas Publishing House Pvt. Ltd.

Vogel, A. I. (1989). Vogel's Textbook of Quantitative Chemical Analysis ( $5^{\text {th }}$ ed.) Great Britain: Bath Press Ltd.

Vogel, A. J. (2001). Vogel's Qualitative Inorganic Analysis ( $7^{\text {th }}$ ed.). India: Thomson Press Ltd. 